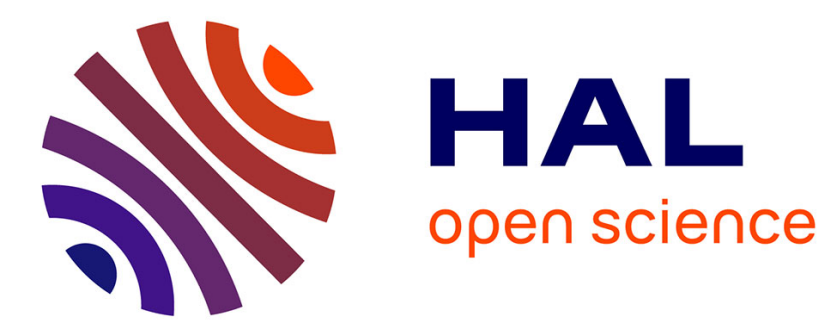

\title{
Regards croisés sur la communication et la trace numériques
}

Dominique Desbois

\section{To cite this version:}

Dominique Desbois. Regards croisés sur la communication et la trace numériques. Terminal. Technologie de l'information, culture \& société, 2021, 10.4000/terminal.7785 . hal-03265845

\section{HAL Id: hal-03265845 \\ https://hal.science/hal-03265845}

Submitted on 21 Jun 2021

HAL is a multi-disciplinary open access archive for the deposit and dissemination of scientific research documents, whether they are published or not. The documents may come from teaching and research institutions in France or abroad, or from public or private research centers.
L'archive ouverte pluridisciplinaire HAL, est destinée au dépôt et à la diffusion de documents scientifiques de niveau recherche, publiés ou non, émanant des établissements d'enseignement et de recherche français ou étrangers, des laboratoires publics ou privés.

\section{다(1)(2)}

Distributed under a Creative Commons Attribution - ShareAlike| 4.0 International 
Regards croisés sur la communication et la trace numériques

Fabien Liénard et Sami Zlitni

Presses universitaires de Rouen et du Havre, Mont Saint Agnan, 2021, 234 pages, $19 €$.

Cet ouvrage collectif se propose d'explorer un paradigme qui assimile l'homme à une entité informationnelle, aux signes-traces qu'il produit au gré de ses échanges. La trace y est définie comme une configuration d'objets, de discours et d'idées qui, par extension conceptuelle de la trace physique, correspond à une pratique sociale s'inscrivant dans un lieu, une temporalité et in fine une culture spécifique. L'humanité serait ainsi à la fois productrice et produit de traces.

La traçabilité d'une action sociale résulte donc de l'usage d'un dispositif de diffusion où la médiation renvoie au contexte social de diffusion et la médiatisation désigne le fait qu'on utilise un support technique. Ainsi la trace numérique devient "une réalité augmentée par des dispositifs sociotechniques " susceptible de s'inscrire dans une logique de manipulation du réel. La " communication électronique " intègre l'ensemble de ces dispositifs socio-techniques relevant des technologies de l'information et de la communication utilisée par les plates-formes numériques du monde entier. L'identité numérique est alors la somme des traces numériques pouvant être rapportées à un individu ou une collectivité, que ces traces soient " profilaires ", " navigationnelles ", " inscriptibles » ou plus simplement déclaratives.

Du fait de leur volume de production et de leur échelle de diffusion, la collecte de traces numériques pose d'emblée de nombreux défis méthodologiques ayant trait à l'exhaustivité ou à la représentativité nécessaires à l'analyse scientifique de leurs impacts socio-économiques. Selon cet ouvrage, Les recherches en sciences de l'information et de la communication continuent de s'interroger sur des méthodologies à (ré)inventer, hésitant à choisir entre corpus, consultation ou recueil en fonction de positionnements théoriques qui vont du positivisme sociologique au constructivisme social. Ainsi, le numérique produirait-il des traces qui, assemblées sur des platesformes, laisseraient leurs empreintes en vue de susciter une réactivité susceptible de produire rankings ou patterns dont il revient aux chercheurs de découvrir la signification.

Ce volume s'ouvre sur une contribution de Béatrice Galinon-Mélénec qui entend faire œuvre épistémologique en abordant l'ichnologie (étude des traces) numérique à travers trois axiomes : la prééminence de la réalité, la singularité des corps et la complexité des traces du point de vue de leurs conséquences.

S'appuyant sur les propositions conceptuelles de Ferdinand de Saussure, de Carles Pierce et de Roland Barthes, Alexandra Saemmer propose des "prolégomènes" à une sémiotique sociale constitués à partir d'un certain nombre de situations expérimentales où des étudiants s'interrogent sur les facteurs matériels et cognitifs qui interviennent dans l'élaboration du sens.

Une expérience de visite marketing à la Cité du Vin de Bordeaux permet à Jean-Jacques Boutaud d'en analyser les traces immersives s'appuyant sur le sensoriel de l'expérience en termes de figuration pour les distinguer des traces post-expériencielles s'appuyant sur les dispositifs de médiatisation personnelle pour la reconfiguration de cette expérience.

Critiquant les dénominations socio-générationnelles qui fleurissent dans la production des essayistes comme des journalistes pour catégoriser les usages numériques, la contribution de Pascal Lardellier 
vise à la déconstruction sociologique de mythes médiatiques en pourfendant notamment celui de la " génération $\mathrm{Y}$ ».

Dans un chapitre consacré à l'interopérabilité des bibliothèques numériques, Fabrice Papy montre que les injonctions politiques autour de la société de l'information ne suffisent pas malgré la création d'infrastructures documentaires numériques interopérables à susciter l'adhésion d'un public aux profils technico-informationnels très disparates, faute sans doute d'une médiation économique pertinente.

Karine Berthelot-Guiet nous propose une réflexion sur les stratégies discursives des marques sur les réseaux sociaux numériques, montrant le renforcement de l'aura de la marque occultant les caractéristiques du produit et s'étendant jusqu'à des discours non-publicitaires pour atteindre à l'ubiquité dans la vie quotidienne.

Une analyse empirique de l'espace médiatique réunionnais nous est proposée par Bernard Idelson et Élodie Lauret mettant en lumière le rapport entre médias et politiques redéfini par les réseaux sociaux à l'échelle du territoire. Les évolutions constatées témoignent de prétentions manifestes des annonceurs à juger du contenu rédactionnel et une plus grande confusion entre information et publicité.

Enfin, une analyse des urbanités numériques par Marie-Anne Paveau met en évidence l'iconisation du discours qui s'opère à travers les usages des applications mobiles notamment dans l'élection de micro-célébrités et la stylisation du soi via le support de la téléphonie mobile.

Dominique Desbois 